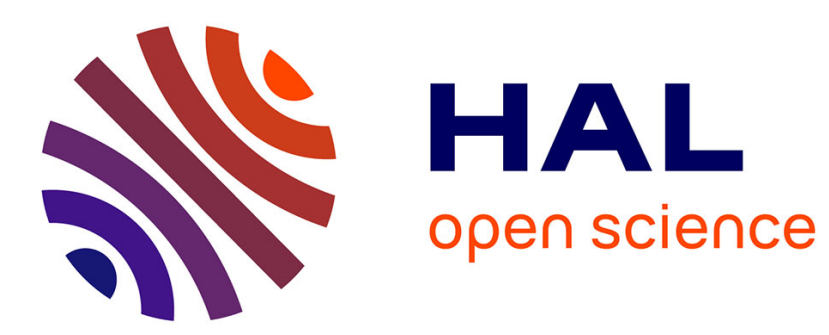

\title{
Structural changes, cointegration and the empirics of Thirlwall's law
}

Alberto Bagnai

\section{To cite this version:}

Alberto Bagnai. Structural changes, cointegration and the empirics of Thirlwall's law. Applied Economics, 2010, 42 (10), pp.1315-1329. 10.1080/00036840701721299 . hal-00588679

\section{HAL Id: hal-00588679}

\section{https://hal.science/hal-00588679}

Submitted on 26 Apr 2011

HAL is a multi-disciplinary open access archive for the deposit and dissemination of scientific research documents, whether they are published or not. The documents may come from teaching and research institutions in France or abroad, or from public or private research centers.
L'archive ouverte pluridisciplinaire HAL, est destinée au dépôt et à la diffusion de documents scientifiques de niveau recherche, publiés ou non, émanant des établissements d'enseignement et de recherche français ou étrangers, des laboratoires publics ou privés. 


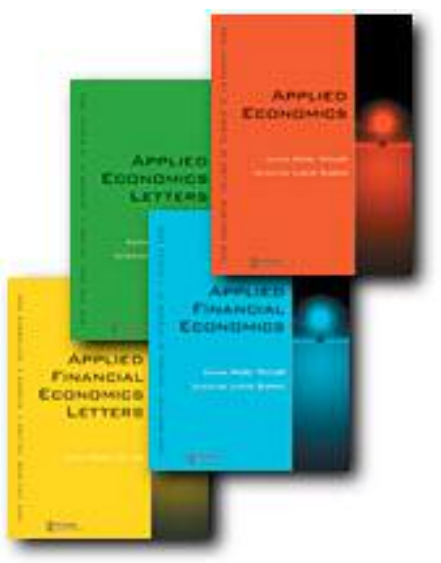

Structural changes, cointegration and the empirics of Thirlwall's law

\begin{tabular}{|r|l|}
\hline Journal: & Applied Economics \\
\hline Manuscript ID: & APE-06-0592.R1 \\
\hline Journal Selection: & Applied Economics \\
\hline Author: & 18-Jan-2007 \\
\hline Complete List of Authors: & $\begin{array}{l}\text { Bagnai, Alberto; University Gabriele D'Annunzio, Dipartimento di } \\
\text { Economia e Storia del Territorio }\end{array}$ \\
\hline JEL Code: & $\begin{array}{l}\text { F43 - Economic Growth of Open Economies < F4 - Macroeconomic } \\
\text { Aspects of International Trade and Finance < F - International } \\
\text { Economics, O40 - General < O4 - Economic Growth and Aggregate } \\
\text { Productivity < O - Economic Development, Technological Change, } \\
\text { and Growth, O57 - Comparative Studies of Countries < O5 - } \\
\text { Economywide Country Studies < O - Economic Development, } \\
\text { Technological Change, and Growth }\end{array}$ \\
\hline Keywords: & $\begin{array}{l}\text { F43 - Economic Growth of Open Economies < F4 - Macroeconomic } \\
\text { Aspects of International Trade and Finance < F - International } \\
\text { Economics, O40 - General < O4 - Economic Growth and Aggregate } \\
\text { Productivity < O - Economic Development, Technological Change, } \\
\text { and Growth, O57 - Comparative Studies of Countries < O5 - } \\
\text { Economywide Country Studies < O - Economic Development, } \\
\text { Technological Change, and Growth }\end{array}$ \\
\hline
\end{tabular}

\section{\$) ScholaroNE \\ Manuscript Central}




\title{
STRUCTURAL CHANGES, COINTEGRATION AND THE EMPIRICS OF THIRLWALL'S LAW
}

\author{
Alberto Bagnai \\ Dipartimento di Economia e Storia del Territorio \\ Università "Gabriele D’Annunzio" \\ viale Pindaro, 42, I-65127, Pescara \\ alberto@bagnai.org \\ http://bagnai.org
}

Abstract - Thirlwall's law establishes a relation between the long-run growth rate, the growth of exports and the long-run income elasticity of imports. The estimation of this parameter requires cointegration techniques, which in turn require a large span of data, thus exposing the estimates to risks of structural changes. While this problem has been recognized in the literature, the evidence produced is still partial, being concerned with a very limited number of countries, and in some respect unsatisfactory. In this paper we fill this gap by assessing Thirlwall's empirical regularity on a sample of 22 OECD countries using econometric techniques that allows for the presence of shift of unknown date in the long-run parameters. The results are generally supportive of Thirlwall's hypothesis and allow us to reconcile and qualify the evidence provided in the existing literature.

JEL: F43, O40, 057. 


\section{STRUCTURAL CHANGES, COINTEGRATION AND THE EMPIRICS OF THIRLWALL'S LAW}

\section{Introduction}

Neo-classical theory explains growth rate differentials between countries in terms of differences in the growth of factor supplies and productivity, using the aggregate production function. According to Thirlwall (1979), this "supply side" explanation is not satisfactory, because it fails to clarify why the dynamics of factor supplies and productivity differ between countries. If supply adapts to demand, as in the standard Keynesian model, these differences should be ascribed to discrepancies in aggregate demand growth rates; these in turn are originated by the existence of long-run constraints on demand growth, imposed by the requirement that in the long run the current account should be in equilibrium. Using an aggregate Keynesian model, Thirlwall (1979) demonstrates that the aggregate demand growth rate compatible with the external equilibrium $\dot{Y}_{B}$ is given by the ratio of the rate of growth of exports $\dot{X}$ to the long-run income elasticity of imports $\pi$; using estimates of the long-run elasticity $\pi$ produced by Houthakker and Magee (1969), Thirlwall (1979) shows that the equation $\dot{Y}_{B}=\dot{X} / \pi$, approximates closely the growth experience of the major economies.

The empirical regularity established by Thirlwall (1979), referred to as "Thirlwall's law" in the literature, has important implications, both for positive economics (where it opposes neoclassical explanations of growth rate differentials), and for normative economics (because it implies, among other things, that a successful economic policy must take into account the income elasticities of exports and imports, and that a tight demand policy pursued by a country may bind the growth rates of a whole area). Given the importance of these implications, the doubts raised by 
McCombie (1981) and McGregor and Swales (1985) on the validity of Thirlwall's results have promoted a long debate ${ }^{1}$. The contributions to this debate agree on two related points: first, the law starts from, and aims at establishing, an empirical regularity (Thirlwall, 1997): therefore, its status and its success as an alternative model of economic growth differentials rest on the validity of the underlying empirical results (McCombie, 1997). Second, the law is concerned with long-run growth; as a consequence, when it comes to the verification of Thirwall's law, the elasticities involved should derive from long-run estimates of the relevant behavioural functions (Hieke, 1997; Atesoglu, 1997). It comes therefore as no surprise that the cointegration approach, promoted by Engle and Granger (1987) as the appropriate econometric tool for investigating long-run relationships between non stationary variables, has had a relevant impact on this debate. Since the study of Bairam (1993), several attempts have been carried out to verify Thirlwall's law using cointegration theory. While broadly supportive of Thirlwall's law, these studies consider generally a very small set of developed countries (the US in Hieke, 1997, and Atesoglu, 1997; five European countries in Bairam, 1993). To our knowledge, there has been to date no attempt to verify the Thirwall's law using cointegration theory on a sample of countries comparable in size with those utilized by Thirlwall (1979) in its seminal contribution. A first purpose of this paper is to fill this gap by verifying the Thirlwall conjecture with cointegration methods in the 22 OECD countries for which the data are available.

The fundamental intuition of the cointegration approach is that in order to assess whether a set of trending variables is tied by a long-run economic relationship, we shall observe whether they move

${ }^{1}$ Among the first contributions we recall Thirlwall $(1979,1981,1986)$, Thirlwall and Hussain (1982), McCombie (1985, 1989, 1992), McGregor and Swales (1986, 1991), Bairam (1988), Fagerberg (1988), Bairam and Dempster (1991). 
together in the long-run without drifting far apart. Therefore, the availability of large samples is crucial to the empirics of cointegration. As a matter of fact, the longer is the sample, the higher the probability that the parameters of any given behavioural function undergo a structural change. This applies in particular to the trade equations involved in Thirlwall's law, because a number of theoretical arguments and empirical results suggest that the income elasticities that feature in the model are very likely to be subject to structural changes over time. This raises some important empirical issues: ignoring the existence of a structural break is a particular case of specification error and leads to biased and inconsistent estimates of a model's parameter; moreover, in the presence of structural breaks the cointegration tests are biased in favour of the null hypothesis of non cointegration, which means that the researcher may be unable to detect an existing long-run relationship (Gregory and Hansen, 1996).

A number of recent contributions assess the impact of structural breaks on the empirical performance of Thirlwall's law (Hieke, 1997; McCombie, 1997; Atesoglu, 1997; Bairam and Ng, 2001). As we shall see in the following, the evidence produced in this field of research is still very limited: a second purpose of this paper is to fill this gap by investigating systematically the presence of structural breaks in the long-run income elasticity of imports and their impact on the predictive performance of Thirlwall's law. To this end we apply to the estimation of the relevant import functions the estimator proposed by Gregory and Hansen (1996), that estimates a long-run relation subject to the presence of a structural break of unknown date.

The paper falls in six sections. After this introduction, Thirlwall's law will be expounded briefly in section 2; section 3 reviews the empirical literature on cointegration and structural change in long-run international trade, focussing on the implications for balance-of-payments constrained growth; section 4 sketches the 
empirical methodology; section 5 presents the empirical results, and section 6 concludes.

2. Thirlwall's law

Thirlwall (1979) starts from the assumption that the demand functions for imports and exports are log-linear and homogeneous of degree zero in prices:

$$
X=\left(\frac{P_{d}}{P_{f}}\right)^{\eta} Z^{\varepsilon} ; M=\left(\frac{P_{d}}{P_{f}}\right)^{\theta} Y^{\pi}
$$

where $X, M, Y$ and $Z$ are the flows of exports, imports, domestic and world income in real terms, $P_{f}$ and $P_{d}$ are the world and foreign prices, measured in a common currency, $\eta<0$ and $\theta>0$ are the price elasticities, and $\varepsilon$ and $\pi$ (both positive) are the income elasticities of exports and imports, respectively. Log-linearising (1), differentiating with respect to time and imposing the long-run requirement that the current account be balanced $(X=M)$ we obtain:

$$
\eta\left(\dot{P}_{d}-\dot{P}_{f}\right)+\varepsilon \dot{Z}=\theta\left(\dot{P}_{d}-\dot{P}_{f}\right)+\pi \dot{Y}
$$

where the points denote the growth rates of the relevant variables. Assuming that relative prices are constant over time $\dot{P}_{d}-\dot{P}_{f}=0,2$ and solving for $\dot{Y}$, we obtain the balance of payments equilibrium growth rate $\dot{Y}_{B}$ :

$$
\dot{Y}_{B}=\frac{\varepsilon \dot{Z}}{\pi}
$$

that can also be expressed as:

2 The same result obtains by assuming that the Marshall-Lerner condition holds as an equality throughout the sample; see Thirlwall (1979). 


$$
\dot{Y}_{B}=\frac{\dot{X}}{\pi}
$$

Equations (3) or (4) express the empirical regularity known as Thirlwall's law. ${ }^{3}$ The law imposes an upper limit to the long-run growth rate of an open economy: $\dot{Y}>\dot{Y}_{B}$ entails $\dot{M}>\dot{X}$, an unsustainable state in the long run. According to post-Keynesian authors this limit was actually operating in most economies, whose growth rates were therefore adequately explained by (4). A possible exception is constituted by those countries that experienced political constraints to growth (i.e., restrictive demand management policies, as Germany), or had insufficient productive capacity (as Japan), and had therefore $\dot{Y}<\dot{Y}_{B}$.

The empirical evidence alleged in favour of equation (4) is based on cross-country analysis, conducted using the estimates $\hat{\pi}$ of the income elasticity of imports obtained from the estimation of standard aggregate import function such as the following:

$$
\log M_{t}=\gamma+\pi \log Y_{t}+\theta\left(\log P_{d, t}-\log P_{f, t}\right)+u_{t}
$$

(Houthakker and Magee, 1969). Three tests are proposed in the literature: Thirlwall (1979) compares the average growth rate $\overline{\dot{Y}}$ with an estimate $\hat{\dot{Y}}_{B}=\overline{\dot{X}} / \hat{\pi}$ of the balance of payments equilibrium growth rate (given by the ratio of the average rate of growth of exports $\overline{\dot{X}}$ to the estimate of the income elasticity of imports $\hat{\pi}$ ), using nonparametric methods; McCombie (1989) calculates the equilibrium elasticity $\pi^{\prime}=\overline{\dot{X}} / \overline{\dot{Y}}$ (defined as the value of $\pi$ that ensures that

${ }^{3}$ Although under the hypotheses above specified the two expressions are equivalent at the theoretical level, in empirical studies equation (4) is preferred because of its simplicity and also because the growth rate of world demand involved in equation (3) raises some measurement issues (see Bairam and Ng, 2001), and the study of Bairam (1997) points out that the 
imports and exports are growing at the same rate) and verifies with a $t$ test the hypothesis $H_{0}: \hat{\pi}=\pi^{\prime}$, using the standard errors deriving from the estimation of regression (5); McGregor and Swales (1985, 1986, 1991) and McCombie (1992) estimate the equation:

$$
\hat{\dot{Y}}_{B, i}=a+b \overline{\dot{Y}}_{i}+u_{i} \quad i=1, \ldots, N
$$

for $N$ countries, verifying the hypothesis $H_{0}:(a, b)^{\prime}=(0,1)^{\prime}$. These tests are all based on estimates of the parameter $\pi$; moreover, the test of McCombie (1989) utilises also the estimates of the standard error of $\pi$.

3. Cointegration, structural breaks, and balance-of-paymentconstrained growth: a critical review

As stated in the introduction, there is a general agreement in the literature on the fact that the empirical regularity established by Thirlwall (1979) is related to long-run growth differentials. Therefore, the estimates of the relevant parameters, and in particular of the income elasticity of imports, $\pi$, should come from the estimation of long-run econometric equations. ${ }^{4}$

The first study that accounts explicitly for this fact by using the cointegration approach is Bairam (1993). Using a sample of 20 annual observations (1970-1989) for five European countries, Bairam concludes that the series involved in the import functions are $I(1)$ in all the countries considered, but that there is no evidence of cointegration, with the possible exception of the import function for France. In the absence of cointegration the static equation (5) is spurious in the sense of Phillips (1986), and in particular the estimates of the parameters standard errors are biased and inconsistent, thus preventing standard statistical inference. In this

income elasticity of exports is more likely to undergo structural changes; see Section 3 below.

${ }^{4}$ Since our analysis rests on equation (4), this survey will focus on issues concerning the estimates of the long-run imports functions. 
case however, pre-filtering with the first difference operator produces $I(0)$ variables, and the parameters of the differenced equation

$\Delta \log M_{t}=\beta_{1} \Delta \log Y_{t}+\beta_{2}\left(\Delta \log P_{d, t}-\Delta \log P_{f, t}\right)+\eta_{t}$

can be estimated and tested using standard methods. Therefore, Bairam (1993) interprets the non cointegration result as a rationale for the practice of pre-differencing the variables involved in equation (5), often adopted in previous studies without any particular justification. He goes on by estimating the trade equations with differenced variables and finds that the income elasticities in the differenced equations are all statistically significant, while the price elasticities are not (with the exception of the import price elasticity in the United Kingdom). The main conclusion of Bairam from the methodological point of view is therefore that the utilization of differenced variables, adopted in previous verification of the law, is warranted by the absence of cointegration between the variables.

A closer look at the results of Bairam raises some questions. As a matter of fact, it is well known since at least Granger and Newbold (1974) that differencing the variables in a spurious regression induces a drastic drop in the goodness of fit and in the (spurious) statistical significance of the parameters, while in a cointegrating equation differencing still results in a statistically significant relation. In the case of the trade equation estimated by Bairam, the $R^{2}$ drops from around 0.97 in the level equations to around 0.8 in the differenced equations, which is still very high. We may therefore question the validity of the non cointegration findings. In fact, the sample adopted by Bairam, while relatively large on calendar terms (20 years), is still quite limited on statistical grounds. In particular, the critical values used for the cointegration tests appear to be those of Engle and Yoo (1987), calculated for a sample of 50 observations 
(i.e., a sample featuring more than twice the observations used by Bairam). Appropriate critical values for cointegration in small samples have been derived by Blangiewicz and Charemza (1990). The $10 \%$ critical value for a regression with two explanatory variables and 20 observations is $\mathbf{- 2 . 8}$. Using this appropriate critical value, we find cointegration in the import functions for three out of the five countries considered (Belgium, France and the United Kingdom). In other words, cointegration (at least in the import functions) appears no longer to be an exception. This explains why differencing the variables does not destroy the statistical significance of the coefficient in the import functions.

This result has a direct relevance for the debate on Thirlwall's law. It has already been noticed by Hieke (1997) and Atesoglu (1997) that in case of cointegration the adoption of differenced variables is inappropriate as it leads to the loss of long-run information. These authors do not provide an explanation of their claim, which was therefore dismissed as irrelevant by McCombie (1997). It is easily shown however that this point is extremely relevant. In fact, the representation theorem of Engle and Granger (1987) demonstrates that two $I(1)$ variables, $y_{t}$ and $x t$, tied by a cointegrating relation, admit a dynamic error correction representation:

$$
\Delta \boldsymbol{y}_{t}=\beta_{0}+\beta_{1} \Delta \boldsymbol{x}_{t}+\beta_{2} z_{t-1}+\varepsilon t
$$

where $z_{t-1}$ is the lagged residual of the static equation of $y_{t}$ on $x_{t}$ (the result extends directly to the case of $n$ variables). If equation (5) cointegrates, its error correction representation is

$$
\Delta \log M_{t}=\beta_{0}+\beta_{1} \Delta \log Y_{t}+\beta_{2}\left(\Delta \log P_{d, t}-\Delta \log P_{f, t}\right)+\beta_{3} \hat{u}_{t-1}+
$$
$\varepsilon_{t}$

where $\hat{u}_{t-1}$ is the lagged OLS residual from equation (5). Therefore, in case of cointegration estimating the differenced equation (7) amounts at dropping from the true dynamic equation (8) the relevant 
variable $\hat{u}_{t-1}$ (the cointegrating residual). This kind of specification error is known to produce biased and inconsistent estimates of the coefficients of the included variables. In other words, if the import function cointegrates, the estimated elasticities from equation (7) are inconsistent. 5

As a matter of fact, and despite Bairam's claim, these conclusions do not change sensibly whenever the variables involved in the function do not cointegrate. In fact, the most likely source of non cointegration is the omission of a relevant variable, of which the presence of a structural break is a particular case (Gregory and Hansen, 1996; Park and Hahn, 1999). In any case, if a relevant variable is omitted from the level equation, it is still omitted from the differenced equation. Therefore, differencing does not per se solve the problem.

Since the cointegration approach requires a large span of data, and since any economic relation is likely to change its structure over the long-run, any application of the cointegration theory is potentially subject to structural breaks problems. This applies in particular to the estimation of trade equations such as those needed for verifying the Thirlwall's law. Thirlwall (1979) first remarked that the import income elasticity may be subject to structural change and in particular that they may have increased towards the end of his sample (ranging from 1951 to 1976). A number of facts may be invoked to explain this pattern: the relaxation of trade barriers and the progress of economic integration, changes in non price competitiveness, improvements in the trade technology, and the level of economic development (see Rose, 1991; Krugman, 1995; McCombie, 1997). An explicit reference to the verification of

5 The argument of McCombie (1997), according to which since Thirlwall's law is concerned with long-run growth rates the use of growth rates does not determine a loss of information, clearly misses the point that in the law features a long-run, rather than an impact, elasticity, and that the 
Thirlwall's law is made by Bairam (1997), that investigates the relation between the level of economic development and the size of the imports and exports income elasticities. He finds that the income elasticity of exports is inversely related to the level of economic development, while the income elasticity of imports is more stable across countries. He concludes that empirical analyses of Thirlwall's law should focus on equation (4), rather than on the theoretically equivalent expression (3). ${ }^{6}$ Following these results, subsequent tests of Thirlwall's law within the cointegration approach have taken into account the presence of structural breaks. ${ }^{7}$

Hieke (1997) considers the case of the United States, using a sample of quarterly data from 1950:1 to 1990:4. ${ }^{8}$ He finds that cointegration does not apply over the whole sample. He then tests for cointegration over several sample splits and finds that cointegration holds generally in the subsamples, provided that the relative prices of imports are included in the equation. The results of Hieke have a number of interesting implications: first, they show clearly that the lack of cointegration can be determined by the omission of a relevant variable from the estimated function: in particular, at least in the United States it appears that relative prices do matter. This indicates that the lack of statistical significance of the estimated relative price elasticities, often found in the empirical literature (Bairam, 1988, 1993), may depend on the adoption of incorrect econometric methodology. Second, Hieke's results suggest that cross-

levels of the variables are needed in order to obtain consistent estimates of this parameter.

${ }^{6}$ By the way, equation (4) appears preferable also because it involves only one estimated parameter, instead of the ratio of two estimated parameters, and is therefore less subject to sample variability

7 Previous analyses of the impact of structural breaks on the performance of Thirlwall's law outside the cointegration approach include Atesoglu (1993, 1995).

8 The increase in the sample size determined by the adoption of higher frequency data is more apparent than real, since what matters for cointegration analysis is the span, rather than the number, of the observation (Otero and Smith, 2000). 
country verification of the Thirlwall's law should consider different sample size in each country, in order to accommodate for the possible presence of structural breaks. The empirical results provided in Section 5 below build on this suggestion by adopting different sample splits in different countries.

However, the analysis of Hieke suffers of two limits: first, the evidence provided is limited, as it considers only a single country, the United States; second, the dates of the structural breaks are arbitrarily chosen, rather than derived from an analysis of the data. McCombie (1997) removes the first limit by considering two more countries (Japan and the United Kingdom). Using annual data from 1952 to 1993 , he first tests the stationarity of the data with both the conventional ADF test of Dickey and Fuller (1979) and Perron's (1993) tests, that verify the null hypothesis of unit root against the alternative of a segmented trend with known break date. Even including a segmented trend with break in 1973, McCombie is unable to reject the null of nonstationarity of imports and income. He then estimates the import functions allowing for a shift in the intercept and in the income elasticity as follows

$$
\log M_{t}=\gamma+\mu_{0} \delta_{t}+\left(\pi+\mu_{1} \delta t\right) \log Y_{t}+\theta\left(\log P_{d, t} \log P_{f, t}\right)+u_{t}
$$

where $\delta_{t}$ is a shift dummy variable that take values zero from the beginning of the sample to 1973 and one from 1974 onwards. He finds that the shift parameters $\mu_{0}$ and $\mu_{1}$ are strongly significant, but that taking into account the structural change in such a way does not allow the reseacher to reject the null of non cointegration, with the exception of Japan. He therefore advocates, in the same way as Bairam (1993), the adoption of pre-differenced variables.

As mentioned before, pre-differencing is likely to be an inadequate response to non cointegration. Besides that, a number of other features are unsatisfactory in McCombie analysis. First, the date of the structural break needs not to be equal in every country 
(as correctly pointed out by Hieke, 1997). Second, even if in a regression with stationary variables a (joint) significance test on the shift dummy variables $\delta_{t}$ is equivalent to the Chow's (1960) test for structural breaks (Gujarati, 1970), standard inference procedures are inapplicable in a regression with integrated variables: therefore, in this particular case we cannot conclude for the significance of a parameter shift by looking at its Student's $t$. Third, in the same way as the introduction of a segmented trend in the ADF regression induces a change in the distribution of the ADF test, the cointegration statistics after the introduction of a structural shift in the long-run parameters cannot be confronted with the usual CRADF critical values (Gregory and Hansen, 1996).

Bairam and Ng (2001) extend the analysis to three other countries (Canada, New Zealand and the UK) and remove another common limit of the previous studies, namely, the arbitrary determination of the break date, by using tests for structural breaks of unknown date. Using a sample of annual data from 1973 to 1995, they find that the trade equations do not cointegrate in Canada and the United Kingdom, while cointegration is found for New Zealand. They take this result as an indication of the fact that the elasticities in the first two countries are subject to structural breaks and verify this hypothesis using the CUSUM test of Brown, Durbin and Evans (1975). While their intuition that the lack of cointegration may depend on structural breaks is fundamentally correct, as we shall see in the following, the use of the CUSUM test is inappropriate in this context, as its distributional properties rest on the assumption of stationarity of the underlying variables, which is found to be violated by Bairam and Ng themselves.

While most theoretical arguments suggest that the parameter of the trade equation should evolve slowly over time (see for instance McCombie, 1997), the empirical verifications surveyed above assume generally that the break points occur in a definite point of the sample, determining a step change in the size of the relevant 
parameters. Although in contrast with the underlying theoretical reasoning, this approach is in line with the empirical results obtained by Ben-David and Papell (1997), who find that in the postwar period the trade ratios of a large number of industrial and developing countries exhibit a structural break in their time path. These results indicate that the impact of punctual events like the oilprice shocks, the GATT rounds, and the progress of European economic integration, dominates the effect of slowly changing variables such as the trade technology and the tastes of the consumers.

\section{The data and empirical methodology}

Equation (5) was estimated using time series data on real imports $M_{t}$, real GDP, $\boldsymbol{Y}_{t}$, and import relative prices, $\boldsymbol{P}_{d, t} \boldsymbol{P}_{f, t}$, ranging from 1960 to 2006 . The relative price of imports was evaluated as the ratio of GDP deflator to the imports deflator. The analysis was performed for the 22 OECD countries for which the data were available: Australia, Austria, Belgium, Canada, Denmark, Finland, France, Greece, Iceland, Ireland, Italy, Japan, Mexico, the Netherlands, New Zealand, Portugal, Spain, Sweden, Switzerland, Turkey, United Kingdom, and the United States. ${ }^{9}$ All the data comes from the 2006\#1 CD-ROM edition of OECD Economic Outlook database.

The time series of $\log M_{t}, \log Y_{t}$ and $\log \left(\boldsymbol{P}_{\boldsymbol{d}, t} / \boldsymbol{P}_{\boldsymbol{f}, t}\right)$ were first tested for unit roots using the $A D F$ test of Dickey and Fuller (1979). The order of lags in the $A D F$ regression was selected by a model reduction procedure as suggested among others by Enders (2004), while the structure of the deterministic component of the underlying process was specified following the general-to-specific approach

${ }^{9}$ Due to lack of data, the estimation for Canada, Denmark, France, New Zealand and Switzerland was performed over the reduced sample 19662006. 
suggested by Dolado et al. (1990), starting from an auxiliary regression with trend and drift.

The existence of a long-run relation between the variables was tested first by the usual Engle and Granger (1987) cointegrating residual $A D F(C R A D F)$ test in the long-run equation (5). Atesoglu (1997) criticizes the use of the $C R A D F$ test and asserts the superiority of the Johansen (1988) approach to testing for cointegration. ${ }^{10}$ However, Johansen analysis applies the maximum likelihood principle, which rests on the assumption that the distribution of the data is known and constant over time. The possible presence of structural breaks, stressed in most of the existing literature, clearly invalidates this assumption. Moreover, the tests for cointegration in the presence of structural breaks are residual based tests derived within the Engle and Granger framework. It was therefore a natural choice to develop the analysis within this approach.

The order of lags in the $C R A D F$ tests was selected in the same way as in the $A D F$ tests. When the ordinary cointegration test failed to reject the null of non-cointegration, we hypothesized that the nonrejection could depend on the presence of a structural break in the long-run parameters and applied the cointegration estimator proposed by Gregory and Hansen (1996), which tests the null of noncointegration against the alternative of cointegration in the presence of a structural break of unknown date. The breaks are modelled using the dummy variable $\varphi_{\tau} t=I(t>[T \tau))$, where $I$ is the indicator function, $T$ is the sample size $(T=47), \tau$ the relative timing of the change point, and [.) the integer part function. The null of noncointegration was tested against two kinds of breaks: the first one is an intercept or "level" shift

10 Atesoglu (1997) studies the cointegration between two variables (the US GDP and exports). The bias in the Engle and Granger cointegration estimates occurs in the presence of multiple cointegration vectors, which in turn implies that the variable considered are at least three. 
$\log \boldsymbol{M}_{t}=\gamma_{0}+\mu_{0} \varphi_{\tau}+\pi \log \boldsymbol{Y}_{t}+\theta\left(\log \boldsymbol{P}_{\boldsymbol{d}, \boldsymbol{t}}-\log \boldsymbol{P}_{\boldsymbol{f}, \boldsymbol{t}}\right)+u_{t}$

while the second one is a "regime" shift

$\log M_{t}=\gamma_{0}+\mu_{0} \varphi_{\tau} t+\left(\pi_{0}+\mu_{1} \varphi_{\tau}\right) \log \boldsymbol{Y}_{t}+\left(\theta_{0}+\mu_{2} \varphi_{\tau}\right)\left(\log \boldsymbol{P}_{\boldsymbol{d}, t}-\log \boldsymbol{P}_{\boldsymbol{f}, \boldsymbol{t}}\right)+$ $u_{t}$

where the $\gamma_{0}, \pi_{0}$ and $\theta_{0}$ indicate the values taken in the first subsample, $\varphi_{\tau}$ is the shift dummy variable defined before, the $\mu_{i}(i=0$, 1,2) are the parameter shifts, so that the parameters in the second subsample can be defined as $\gamma_{1}=\gamma_{0}+\mu_{0}, \pi_{1}=\pi_{0}+\mu_{1}$ and $\theta_{1}=\theta_{0}+\mu_{2}$, and $u_{t}$ is the cointegrating residual. When $\mu_{i}=0(i=0,1,2)$ equations (10) and (11) reduce to equation (5). In the "level shift" model (10) only the intercept undergoes a structural break shifting by an amount $\mu_{0}$ starting in $t>[T \tau)$. In this case the income and price elasticities are unaffected. In the "regime shift" model (11) all the parameters of the long-run equation are allowed to change. Equation (11) is more general than the equation (9) estimated by McCombie (1997) both because the date of the structural break is unknown and because all the long-run parameters are allowed to vary.

The test statistic is evaluated as $A D F_{r}^{*}=\inf _{\tau} A D F_{r}(\tau)$, where $A D F_{r}(\tau)$ is the cointegrating $A D F$ statistic calculated using the OLS residuals in model $r(r=L, R$, where " $L$ " indicates the "level shift" and " $R$ " the "regime shift" model). ${ }^{11}$ In other words, $A D F_{r}^{*}$ is the smallest among all the ADF statistics that can be evaluated in model $r$ across all possible dates of structural breaks. As we generally had no a priori information on the shape of the relevant alternative, we calculated the $A D F_{r}{ }^{*}$ statistics for each of the two models $L$, and $\boldsymbol{R}$. Where the null of non-cointegration was rejected in favour of more

11 The order of lags in the auxiliary $A D F$ regression was selected as explained in the preceding footnote 4 . 
than one alternative, we chose either the model corresponding to the more significant statistic, or that with the more meaningful parameters from the point of view of economic theory. The break date $T_{1}=[\tau T)$ reported refers to the last year of the first regime (i.e., the change occurs between $T_{1}$ and $\left.T_{1}+1\right)$.

Equations (9), (10) and (11) clarify the relation between structural breaks and specification errors. If a structural break is present in the data, estimating the equation over the whole sample amounts at omitting the statistically significant terms involving the shift dummy $\delta_{t}$ or $\varphi_{\tau}$. Irrespective of the nature of the variables involved, this kind of specification error leads to biased and inconsistent estimates. In case of a regression between non stationary variables, this specification error leads also to non rejection of the non cointegration hypothesis.

\section{Results}

\subsection{Unit root tests}

The results of the unit root tests are summarized in Table 1. The time series of real imports appear to be $I(1)$ in 20 out of 22 cases, the only exceptions being France and Switzerland, where the series appear to be trend stationary; in 14 out of 20 cases the $I(1)$ series of real imports display a significant drift. Similar findings apply to the real GDP series, which result to be $I(1)$ in 18 out of 22 cases, the exceptions being in this case Denmark, France, Switzerland and the USA, where the GDP series appear to be generated by a deterministic trend process. As far as the import relative prices are concerned, the unit root hypothesis is rejected only for Austria, Belgium, Canada, Iceland, Switzerland and Turkey. In the other 16 countries the PPP, measured using the import relative prices, does not hold. Strictly speaking, the same conclusion applies to Iceland, where the relative prices appear to follow a deterministic trend. 
Summing up the results, the standard import functions results in an unbalanced cointegration relation only in France, where the stochastic trend in relative prices does not match the deterministic trend in real imports. In the case of Switzerland the import function elasticities could be estimated in the usual way, after detrending the import and GDP series, and the possible presence of structural breaks could be explored using the test of Andrews (1993) or its generalization by Bai and Perron (1998). In the other 20 cases the cointegration approach is always warranted, because the stochastic trend in the import series is matched by a stochastic trend in at least one of the two explanatory variables.

\subsection{Cointegration tests on the aggregate import function}

Table 2 reports the results of the cointegration test on the import function (5). A stable long-run import function is found in only five out of 22 cases, namely for Austria, Portugal, Spain, Turkey and the United States. In another eleven cases (Australia, Belgium, Canada, Denmark, Finland, Greece, Iceland, the Netherlands, New Zealand, Sweden, and the United Kingdom) cointegration is found once we allow for a structural break in the parameters. ${ }^{12}$ In eight out of these eleven cases the structural shift involves all the parameters of the estimated equation. The structural break dates are not always easy to interpret. In some cases they do coincide with major institutional changes, such as the accession to free trade areas or other international agreements. For instance, the structural break in Sweden coincides with its accession to the European Union (EU), and that in Greece follows the accession to the EU; the break in Canada import function coincides with the coming into effect of the NAFTA; the break in Iceland occurs during the Uruguay round, that had important implications for the economic integration of this

12 In the cases of Finland and New Zealand the non cointegration hypothesis is rejected at the $10 \%$ level without considering a structural break and at the $5 \%$ level once a structural break is taken into account. 
country, and so on. Contrary to what is assumed in previous studies (e.g., McCombie, 1997), the oil-price shocks do not appear to have exerted a strong impact on the income elasticities of imports. This explains why in these studies imposing a break in 1973 does not result generally in a sensible long-run equation.

In the remaining six cases the cointegration tests are unable to find a stable long-run relation: this applies to France, Ireland, Italy, Japan, Mexico and Switzerland. In the cases of France and Switzerland this result is expected, since, as stated before, the import function is unbalanced in France, and requires detrended import and income series in Switzerland. In the other four cases (Ireland, Italy, Japan and Mexico) the non cointegration result may depend on the presence of multiple structural breaks. A glance at the residuals of the long-run estimates, reported in Figure 1, shows that this could indeed be the case: the cointegrating residual in these countries features at least two distinct breaks, located generally at the beginning of the Seventies and at the end of the Nineties. ${ }^{13}$

\subsection{Structural breaks and balance-of-payments constrained growth}

We now check for the impact of structural breaks on the empirical performance of Thirlwall's law. Table 3 reports the estimated income elasticities of imports, $\hat{\pi}$, along with the estimates reported in some previous studies, and Table 4 compares the balance of payments constrained growth rates evaluated under the maintained hypothesis of no structural break, using the $\hat{\pi}$ reported in Table 3. In order to gauge the contribution of the cointegration with structural break analysis, the comparison in Table 4 includes

13 An anonymous referee pointed out that these cases could be coped with by using the test for panel cointegration with multiple structural breaks proposed by Westerlund (2006). We acknowledge gratefully this suggestion. However, Westerlund's (2006) test allows for multiple breaks in the deterministic components of the individual regressions. This corresponds to a panel version of the "level shift" model (equation (10) above), and is therefore unsuited to detect the possible presence of multiple "regime shifts" (i.e., breaks in the long-run elasticities). 
also the cases of non cointegration, as it was common practice in most empirical verifications of Thirlwall's law. As is to be expected, the results are broadly consistent with those reported in previous studies: the rank correlation between the actual and the estimated growth rate is about 0.7 , with an average absolute deviation between the two rates equal to 0.8 per cent points. The worst performers are mostly located in the EU periphery: Ireland (with an overestimation of 2.3 per cent points), Italy (with an overestimation of 1.9 per cent points), and Greece (with an underestimation of 1.67 per cent points). However, we know from Table 2 that the long-run estimates for these countries are unreliable.

Table 5 repeats the comparison after dropping the six countries for which we were unable to estimate a long-run import function. When cointegration occurs after considering a structural break, the Table reports separately the pre- and post-break estimates. When cointegration occurs without a structural break, the pre- and postbreak values of $\dot{Y}_{B}$ and $\dot{Y}$ coincide.

The results show that the inclusion of a structural break has a significant impact on the performance of Thirwall's law, and in particular that the predictive power of this empirical regularity has greatly increased in recent times. In the pre-break subsample the mean absolute deviation is equal to $0.93 \%$, with a rank correlation coefficient of 0.17 , not significantly different from zero, while in the post-break subsample the mean absolute deviation drops to $0.48 \%$ and the rank correlation increases to 0.79 . The same picture emerges from the estimation of equation (6), reported in Table 6. The fit of the model in the pre-break sample is very poor, the linearity test points out inadequacies of the functional form, and the hypothesis $a=0, b=1$ is strongly rejected by the data. In the post-break sample the adjusted $R^{2}$ increases to 0.68 and the model passes all the usual misspecification tests. The hypothesis $a=0, b=1$ is still marginally rejected at the $5 \%$ level, but not at the $1 \%$ level. 
It appears therefore that the explanatory power of the demandside explanations of growth differentials has increased along with the increase of the openness of the OECD countries, i.e., along with the relative increase of the foreign components of aggregate demand over total aggregate demand.

\section{Conclusions}

A number of studies concerned with the assessment of the balance-of-payment constraint on economic growth have recognized that the presence of structural breaks could prevent the estimation of the long-run elasticities involved in Thirlwall's law. While the problem was clearly stated in a number of previous studies, the solutions provided were partial and unsatisfactory, because evidence was provided only for a limited number of countries, conditional on a known break date (generally assumed to be equal across countries), and using statistical inference procedures not always suited to the nature of the data under scrutiny.

In this paper we provided more evidence by using appropriate econometric techniques on a sample of 22 OECD countries. The estimators utilized accounts for both nonstationarity of the variables and the presence of structural changes of unknown date in the relevant parameters.

The main findings can be summarized as follows:

1) by allowing for a structural break of unknown date we are able to find cointegration in 16 out of 22 countries considered; this contrasts strongly with most of the previous evidence, where cointegration in the import demand function was almost invariably found to be the exception, not the rule.

2) The long-run estimates obtained are strongly supportive of Thirlwall's hypothesis only in the second half of the sample; in other words, the strength of the relationship postulated by Thirlwall appears to be directly related 
with the progress of economic integration and with the increased openness of the economic systems under scrutiny.

As for the first point, the results confirm the intuition of Hieke (1997) that the non cointegration findings may depend on ignoring structural breaks in the long-run parameters. Contrary to the conclusions of Bairam (1997) we find that the presence of structural breaks is rather pervasive in import demand functions. Interesting enough, a single step change in the long-run parameters generally restores cointegration, and there is but a limited evidence of multiple breaks. This contrasts the view that structural changes in the trade income elasticities reflects changes in the degree of non price competitiveness, which in turns evolves slowly according to a number of secular factors (McCombie, 1997). A much more significant determinant of structural breaks in trade equations appears to be the accession to free trade agreements. On the contrary, the oil-price shocks, often arbitrarily taken as the source of structural change in trade equations, do not appear to be a major problem in this context.

As for the second point, once the structural breaks in the longrun parameters are taken into account, the approximation of the long-run growth rates provided by equation (4) improves remarkably, going from a mean absolute deviation of 0.93 per cent points in the pre-break sample to a value of 0.48 per cent points in the post-break sample, which is well below the 0.79 obtained in the whole sample. The worse fit in the pre-break sample depends also on the fact that in this subsample a number of countries (Australia, Finland, Greece, Iceland, and the United States) appear to have violated the balance-of-payments constraint. Unsurprisingly enough, these countries are all classified as persistent net external debtors in the study of Lane and Milesi-Ferretti (1999). In some cases the structural breaks coincide with the transition to a more sustainable pattern of external indebtedness: this is the case of Greece and, to a 
lesser extent, of Finland (see figure 2 in Lane and Milesi-Ferretti, 1999). In the post-break subsample all the countries considered appear to have grown at or below the constraint defined by Thirlwall's law, with the only exception of the United States (where the actual growth keeps exceeding $\dot{Y}_{B}$ by 0.30 per cent points), and, to a lesser extent, Denmark (also a debtor country in Lane and MilesiFerretti classification). This result is consistent with the persistent worsening of the US external position, and questions the validity of a number of previous studies, according to which the US economy was balance-of-payment constrained (Hieke, 1997; Atesoglu, 1997). At the same time, a comparison of the pre- and post-break results seems to suggest that the increased attention of governments worldwide for a sustainable path of external indebtedness has contributed to an improvement in the predictive performance of Thirlwall's law.

As shown before, in most previous studies the absence of cointegration, rather than being perceived as a problem, was welcome as a rationale for the practice of predifferencing the variables involved in the model, and the related loss of long-run information was dismissed as being irrelevant in this context. As a matter of fact, a better rationale for preferring the differenced model is offered by the very presence of a structural break. As Hendry and Clements (2003) show, in the presence of shifts in the parameters, first differencing of the variables transforms a persistent break in a single period blip located at the date of the shift. This can be seen by differencing equation (9):

$\Delta \log M_{t}=\gamma+\mu_{0} \Delta \delta_{t}+\left(\pi+\mu_{1} \Delta \delta_{t}\right) \Delta \log \boldsymbol{Y}_{t}+\theta\left(\Delta \log \boldsymbol{P}_{\boldsymbol{d}, t}-\log \Delta \boldsymbol{P}_{\boldsymbol{f}, t}\right)+u_{t}$

and noting that $\Delta \delta_{t}$ has a unique non zero value equal to one located at the date of the structural break. Therefore, differencing the model transforms an omitted variable problem into an outlier problem, or, put it in another way, ignoring a structural break in the differenced model amount at omitting a point, rather than a shift, dummy 
variable. This can be a rather minor problem if the size and signs of the shifts parameters and of the variables at the break date do partially offset. This may explain why in most previous empirical work the differenced trade equations were invariably found to have superior statistical properties.

However, even if for these reasons differenced models can perform better than level equations in terms of short-term forecasting performance, they are still unsuitable, for the reasons recalled in Section 3 above, to the estimation of long-run parameters, which is our concern in the present context. This is a possible explanation of the relatively poor performance of Thirlwall's law in studies based on estimates coming from differenced equations. For instance, Bairam (1988), using a sample of 19 countries, of which 16 overlap those included in this study, considers "small" a mean absolute difference between $\dot{Y}_{B}$ and $\dot{Y}$ equal to about 0.8 per cent points, while we have seen that taking into account the structural shifts reduces the mean absolute difference to about 0.5 per cent points.

While our results appear to support Thirlwall's model as an explanation of long-run growth differential, they point out at the same time some areas for further research. First, there is evidence that some countries underwent multiple structural breaks. Second, Table 1 shows that relative prices are generally nonstationary, which in turn implies that equation (3) and (4) hold only as an approximation. In this case a more accurate expression of the balance-of-payment constraint involves also the relative price elasticities as in Thirlwall (1979), and it would be interesting to verify whether taking into account the price competitiveness would improve the approximation provided by equation (4). Third, the structural break analysis should be extended also to non OECD countries, where the impact of structural changes is likely to be more pervasive. These topics are left for future investigations. 
Acknowledgments

Useful comments from an anonymous referee are gratefully acknowledged. This research was supported by a MIUR grant.

\section{References}

Andrews, D.W.K. (1993) "Tests for parameter instability and structural change with unknown change point", Econometrica, 61, 821-856.

Atesoglu, H.S. (1993) "Balance-of-payments constrained growth: evidence from the United States", Journal of Post Keynesian Economics, 15, 507-514.

Atesoglu, H.S. (1995) "An explanation of the slowdown in U.S. economic growth", Applied Economics Letters, 2, 91-94.

Atesoglu, H.S. (1997) "Balance-of-payments-constrained growth model and its implications for the United States", Journal of Post Keynesian Economics, 19, 327-335.

Bai, J. and P. Perron (1998) "Estimating and testing linear models with multiple structural changes", Econometrica, 66, 47-78.

Bairam, E. (1988) "Balance of payments, the Harrod foreign trade multiplier and economic growth: the European and North American experience, 1970-1985", Applied Economics, 20, 16351642.

Bairam, E. (1993) "Static versus dynamic specifications and the Harrod foreign trade multiplier", Applied Economics, 25, 739742.

Bairam, E. (1997) "Levels of economic development and appropriate specifications of the Harrod foreign-trade multiplier", Journal of Post Keynesian Economics, 19, 337-344.

Bairam, E. and G. Dempster (1991) "The Harrod foreign trade multiplier and economic growth in Asian countries", Applied Economics, 23, 1719-1724. 
Bairam, E. and L. Ng (2001) "Thirlwall's law and the stability of export and import income functions", International Review of Applied Economics, 15, 287-303.

Ben-David, D. and D.H. Papell (1997) "International trade and structural change", Journal of International Economics, 43, 513-523.

Blangiewicz, M. and W.W. Charemza (1990) "Cointegration in small samples: empirical percentiles, drifting moments and customized testing", Oxford Bulletin of Economics and Statistics, 52, 303-315.

Brown, R.L., Durbin, J. and J.M. Evans (1975) “Techniques for testing the constancy of regression relationships over time", Journal of the Royal Statistical Society, series B, 37, 149-192.

Chow, G.C. (1960) "Tests of equality between sets of coefficients in two linear regressions", Econometrica, 28, 591-603.

Dickey, D. and W. Fuller (1979) "Distribution of the estimators for autoregressive time-series with a unit root", Journal of the American Statistical Association, 74, 427-431.

Dickey, D. and W. Fuller (1981) "Likelihood ratio statistics for autoregressive time series with a unit root", Econometrica, 49, 1057-1072.

Dolado, J.J., T. Jenkinson and S. Sosvilla-Rivero (1990) "Cointegration and unit roots", Journal of Economic Surveys, 4, 249-273.

Enders, W. (2004) Applied Econometric Time-Series, 2nd edition, New York: John Wiley and Sons.

Engle, R.F. and C.W.J. Granger (1987) "Cointegration and error correction: representation, estimation and testing", Econometrica, 55, 251-276.

Engle, R.F. and B.S. Yoo (1987) "Forecasting and testing in cointegrated systems", Journal of Econometrics, 35, 143-159.

Fagerberg, J. (1988) "International competitiveness", Economic Journal, 98, 355-374. 
Fuller, W. (1976) Introduction to Statistical Time Series, New York: John Wiley and Sons.

Granger, C.W.J. and P. Newbold (1974) "Spurious regressions in econometrics", Journal of Econometrics, 2, 111-120.

Gregory, A.W. and B.E. Hansen (1996) "Residual-based tests for cointegration in models with regime shifts", Journal of Econometrics, 70, 99-126.

Gujarati, D. (1970) "Use of dummy variables in testing for equality between sets of coefficients in two linear regressions: a note", The American Statistician, 24, 50-52.

Hendry, D.F., and M.P. Clements (2003) "Economic forecasting: some lessons from recent research", Economic Modelling, 20, 301329.

Hieke, H. (1997) "Balance-of-payments-constrained growth: a reconsideration of the evidence for the U.S. economy", Journal of Post Keynesian Economics, 19, 313-325.

Houthakker, H., and S. Magee (1969) "Income and price elasticities in world trade", Review of Economics and Statistics, 51, 111-125.

Johansen, S. (1988) "Statistical analysis of cointegration vectors", Journal of Economic Dynamics and Control, 12, 231-254.

Krugman, P. (1995) "Growing world trade: causes and consequences", Brooking Papers on Economic Activity, 1, 327377.

McCombie, J.S.L. (1981) "Are international growth rates constrained by the balance of payments? A comment on Professor Thirlwall”, Banca Nazionale del Lavoro Quarterly Review, 139, 455-458.

McCombie, J.S.L. (1985) "Economic growth, the Harrod foreign trade multiplier and Hicks super-multiplier", Applied Economics, 17, 55-72.

McCombie, J.S.L. (1989) "Thirlwall's law' and balance of payments constrained growth - a comment on the debate", Applied Economics, 21, 611-629. 
McCombie, J.S.L. (1992) "'Thirlwall's law' and balance of payments constrained growth: more on the debate", Applied Economics, 24, 493-512.

McCombie, J.S.L. (1997) “On the empirics of balance-of-paymentsconstrained growth", Journal of Post Keynesian Economics, 19, 345-375.

McGregor, P.G. and J.K. Swales (1985) "Professor Thirlwall and balance of payments constrained growth", Applied Economics, 17, 17-32.

McGregor, P.G. and J.K. Swales (1986) "Balance of payments constrained growth: a rejoinder to Professor Thirlwall", Applied Economics, 18, 1256-1274.

McGregor, P.G. and J.K. Swales (1991) "Thirlwall's Law and balance of payments constrained growth: further comment on the debate", Applied Economics, 23, 9-20.

Otero, J. and J. Smith (2000) "Testing for cointegration: power versus frequency of observation - further Monte Carlo results", Economics Letters, 67, 5-9.

Park, J.Y. and S.B. Hahn (1999) "Cointegrating regressions with time varying coefficients", Econometric Theory, 15, 664-703.

Phillips, P.C.B. (1986) "Understanding spurious regressions in econometrics", Journal of Econometrics, 33, 311-340.

Thirlwall, A.P. (1979) "The balance of payments constraints as an explanation of international growth rate differences", Banca Nazionale del Lavoro Quarterly Review, 128, 45-53.

Thirlwall, A.P. (1981) “A reply to McCombie", Banca Nazionale del Lavoro Quarterly Review, 139, 458-459.

Thirlwall, A.P. (1986) "Balance of payments constrained growth: a reply to McGregor and Swales", Applied Economics, 18, 12561263.

Thirlwall, A.P. (1997) "Reflections on the concept of balance-ofpayments-constrained growth", Journal of Post Keynesian Economics, 19, 377-385. 
Thirlwall. A.P. and M.N. Hussain (1982) "The balance of payments constraint, capital flows and growth rate differences between developing countries", Oxford Economic Papers, 34, 498-510.

Westerlund, J. (2006) "Testing for panel cointegration with multiple structural breaks", Oxford Bulletin of Economics and Statistics, 68, 101-132. 


\begin{tabular}{|c|c|c|c|c|c|c|c|}
\hline country & series & $\tau_{\tau}$ & $\Phi_{3}$ & $\tau_{\mu}$ & $\Phi_{1}$ & $\tau$ & $p$ \\
\hline \multirow{3}{*}{ Australia } & $\log \mathrm{M}$ & -0.51 & 0.70 & 1.01 & $11.27^{*}$ & & 3 \\
\hline & $\log \mathrm{Y}$ & -2.92 & 5.49 & -1.69 & $10.15^{*}$ & & 2 \\
\hline & $\log \left(\mathrm{P}_{d} / \mathrm{P}_{f}\right)$ & -1.64 & 1.54 & -0.52 & 1.18 & -1.55 & 3 \\
\hline \multirow{3}{*}{ Austria } & $\log \mathrm{M}$ & -2.21 & 4.13 & -2.09 & $14.21^{*}$ & & 1 \\
\hline & $\log \mathrm{Y}$ & -1.58 & 4.79 & -2.90 & $14.58^{*}$ & & 2 \\
\hline & $\log \left(\mathbf{P}_{d} / \mathbf{P}_{f}\right)$ & -2.86 & 4.29 & -1.16 & 2.65 & $-2.22^{*}$ & 2 \\
\hline \multirow{3}{*}{ Belgium } & $\log \mathrm{M}$ & -2.42 & 4.59 & -2.13 & $12.13^{*}$ & & 1 \\
\hline & $\log \mathrm{Y}$ & -2.48 & $8.50^{*}$ & & & & 1 \\
\hline & $\log \left(\mathrm{P}_{d} / \mathrm{P}_{f}\right)$ & -2.38 & 2.89 & -2.11 & 2.35 & $-2.06 *$ & 1 \\
\hline \multirow{3}{*}{ Canada } & $\log \mathrm{M}$ & -2.57 & 3.36 & -0.64 & $6.75^{*}$ & & 1 \\
\hline & $\log \mathrm{Y}$ & -2.70 & 4.61 & -1.56 & $8.63^{*}$ & & 2 \\
\hline & $\log \left(\mathbf{P}_{d} / \mathbf{P}_{f}\right)$ & -2.75 & 3.95 & -2.38 & 2.99 & $-2.46^{*}$ & 1 \\
\hline \multirow{3}{*}{ Denmark } & $\log \mathrm{M}$ & -1.07 & 1.79 & 1.33 & 4.09 & 2.55 & 3 \\
\hline & $\log \mathrm{Y}$ & $-3.55^{*}$ & & & & & 1 \\
\hline & $\log \left(\mathrm{P}_{d} / \mathbf{P}_{f}\right)$ & -2.39 & 2.88 & -0.91 & 1.01 & -1.44 & 2 \\
\hline \multirow{3}{*}{ Finland } & $\log \mathrm{M}$ & -3.00 & 4.79 & -1.07 & 7.34* & & 3 \\
\hline & $\log \mathrm{Y}$ & -3.16 & 5.16 & -1.09 & 1.86 & 1.55 & 4 \\
\hline & $\log \left(\mathrm{P}_{d} / \mathrm{P}_{f}\right)$ & -1.92 & 1.85 & -1.28 & 1.13 & -1.48 & 2 \\
\hline \multirow{3}{*}{ France } & $\log \mathrm{M}$ & $-3.71^{*}$ & & & & & 1 \\
\hline & $\log \mathrm{Y}$ & $-4.60 *$ & & & & & 2 \\
\hline & $\log \left(\mathrm{P}_{d} / \mathrm{P}_{f}\right)$ & -1.02 & 2.47 & 0.28 & 0.62 & -0.62 & 3 \\
\hline \multirow{3}{*}{ Greece } & $\log \mathrm{M}$ & -3.28 & $7.25^{*}$ & & & & 2 \\
\hline & $\log \mathrm{Y}$ & -2.47 & 3.06 & -0.10 & $6.27^{*}$ & & 3 \\
\hline & $\log \left(\mathrm{P}_{d} / \mathrm{P}_{f}\right)$ & -1.66 & 1.88 & 0.08 & 1.51 & -1.35 & 2 \\
\hline \multirow{3}{*}{ Iceland } & $\log \mathrm{M}$ & -2.69 & 3.65 & -0.78 & 3.37 & 2.46 & 3 \\
\hline & $\log \mathrm{Y}$ & -1.19 & 1.49 & 1.04 & $4.87^{*}$ & & 2 \\
\hline & $\log \left(\mathbf{P}_{d} / \mathbf{P}_{f}\right)$ & $-3.96^{*}$ & & & & & 5 \\
\hline \multirow{3}{*}{ Ireland } & $\log \mathrm{M}$ & -1.63 & 1.38 & 0.02 & $5.55^{*}$ & & 2 \\
\hline & $\log \mathrm{Y}$ & -3.50 & 7.93* & & & & 2 \\
\hline & $\log \left(\mathrm{P}_{d} / \mathrm{P}_{f}\right)$ & -2.48 & 3.07 & -1.09 & 1.74 & -1.87 & 1 \\
\hline \multirow{3}{*}{ Italy } & $\log \mathrm{M}$ & -2.83 & 5.56 & -2.06 & $10.92^{*}$ & & 1 \\
\hline & $\log \mathrm{Y}$ & -1.86 & 2.41 & -1.49 & $6.28^{*}$ & & 3 \\
\hline & $\log \left(\mathrm{P}_{d} / \mathrm{P}_{f}\right)$ & -1.95 & 1.93 & -1.55 & 1.47 & -1.71 & \\
\hline \multicolumn{2}{|c|}{$5 \%$ critical values } & -3.50 & 6.73 & -2.93 & 4.86 & -1.95 & \\
\hline
\end{tabular}

Table 1 - Results of the integration tests on the series of real imports, real income and relative prices (all the variables are in logarithms); $\tau_{\tau}, \tau_{\mu}$ and $\tau$ are the Dickey-Fuller statistics for the hypothesis of integration in processes with trend and drift, with drift, and without trend and drift, respectively (Fuller, 1976, tab. 8.5.2); $\Phi_{1}$ and $\Phi_{3}$ are the Dickey-Fuller statistics for the hypothesis that the drift (respectively, the trend) is not statistically significant, conditional on the series being $I(1)$ (Dickey and Fuller, 1981, tab. IV and VI). 


\begin{tabular}{|c|c|c|c|c|c|c|c|}
\hline country & series & $\tau_{\tau}$ & $\Phi_{3}$ & $\tau_{\mu}$ & $\Phi_{1}$ & $\tau$ & $p$ \\
\hline \multirow{3}{*}{ Japan } & $\log \mathrm{M}$ & -2.90 & 4.93 & -1.80 & 3.04 & 1.57 & 5 \\
\hline & $\log \mathrm{Y}$ & -1.49 & $8.73^{*}$ & & & & 2 \\
\hline & $\log \left(\mathrm{P}_{d} / \mathrm{P}_{f}\right)$ & -2.23 & 2.70 & -1.75 & 1.85 & -1.73 & 1 \\
\hline \multirow{3}{*}{ Mexico } & $\log \mathrm{M}$ & -1.97 & 2.11 & 0.08 & 3.73 & 2.76 & 3 \\
\hline & $\log \mathrm{Y}$ & -2.12 & 5.23 & -2.88 & $8.78^{*}$ & & 2 \\
\hline & $\log \left(\mathrm{P}_{d} / \mathrm{P}_{f}\right)$ & -1.36 & 1.47 & -1.37 & 1.00 & -1.38 & 2 \\
\hline \multirow{3}{*}{ Netherlands } & $\log \mathrm{M}$ & -2.71 & 4.36 & -1.54 & $6.44^{*}$ & & 2 \\
\hline & $\log \mathrm{Y}$ & -2.78 & 5.92 & -2.39 & $5.65^{*}$ & & 2 \\
\hline & $\log \left(\mathrm{P}_{d} / \mathrm{P}_{f}\right)$ & -2.09 & 2.22 & -0.70 & 1.85 & -1.80 & 3 \\
\hline \multirow{3}{*}{ NewZealand } & $\log \mathrm{M}$ & -0.98 & 1.26 & 1.05 & $5.00^{*}$ & & 4 \\
\hline & $\log \mathrm{Y}$ & -2.64 & 3.64 & 0.06 & 2.69 & 2.35 & 3 \\
\hline & $\log \left(\mathrm{P}_{d} / \mathrm{P}_{f}\right)$ & -1.84 & 1.96 & -0.45 & 0.74 & -1.17 & 3 \\
\hline \multirow{3}{*}{ Portugal } & $\log \mathrm{M}$ & -2.30 & 2.72 & -0.73 & $5.96^{*}$ & & 1 \\
\hline & $\log \mathrm{Y}$ & -1.79 & 4.90 & -2.88 & $6.19^{*}$ & & 5 \\
\hline & $\log \left(\mathrm{P}_{d} / \mathrm{P}_{f}\right)$ & -1.39 & 1.48 & -0.57 & 0.52 & -1.03 & 1 \\
\hline \multirow{3}{*}{ Spain } & $\log \mathrm{M}$ & -3.10 & 4.82 & -0.34 & 2.02 & 1.97 & 4 \\
\hline & $\log \mathrm{Y}$ & -2.60 & 4.98 & -2.05 & $8.03^{*}$ & & 2 \\
\hline & $\log \left(\mathrm{P}_{d} / \mathrm{P}_{f}\right)$ & -2.70 & 3.67 & -1.24 & 1.59 & -1.80 & 1 \\
\hline \multirow{3}{*}{ Sweden } & $\log \mathrm{M}$ & -2.45 & 3.11 & -0.83 & $9.03^{*}$ & & 1 \\
\hline & $\log \mathrm{Y}$ & -2.92 & 4.49 & -1.04 & 4.18 & 2.66 & 3 \\
\hline & $\log \left(\mathrm{P}_{d} / \mathrm{P}_{f}\right)$ & -1.83 & 1.72 & -1.76 & 1.60 & -1.68 & 3 \\
\hline \multirow{3}{*}{ Switzerland } & $\log \mathrm{M}$ & $-3.99^{*}$ & & & & & 3 \\
\hline & $\log \mathrm{Y}$ & $-4.27^{*}$ & & & & & 3 \\
\hline & $\log \left(\mathrm{P}_{d} / \mathrm{P}_{f}\right)$ & -3.50 & 6.46 & -1.17 & 2.26 & $-2.02^{*}$ & 2 \\
\hline \multirow{3}{*}{ Turkey } & $\log \mathrm{M}$ & -3.36 & 6.21 & 0.61 & $7.98^{*}$ & & 2 \\
\hline & $\log \mathrm{Y}$ & -2.74 & 4.46 & -1.36 & $8.80^{*}$ & & 2 \\
\hline & $\log \left(\mathrm{P}_{d} / \mathrm{P}_{f}\right)$ & -2.33 & 4.26 & -2.93 & 4.41 & $-2.06^{*}$ & 1 \\
\hline \multirow{3}{*}{ UK } & $\log \mathrm{M}$ & -1.24 & 1.23 & 0.78 & $7.68^{*}$ & & 3 \\
\hline & $\log \mathrm{Y}$ & -2.26 & 3.18 & -1.47 & $4.87^{*}$ & & 3 \\
\hline & $\log \left(\mathbf{P}_{d} / \mathbf{P}_{f}\right)$ & -2.21 & 2.93 & -0.42 & 0.72 & -1.21 & 3 \\
\hline \multirow{3}{*}{ USA } & $\log \mathrm{M}$ & -1.97 & 1.96 & -0.06 & $7.67^{*}$ & & 3 \\
\hline & $\log \mathrm{Y}$ & $-4.42^{*}$ & & & & & 3 \\
\hline & $\log \left(\mathbf{P}_{d} \mathbf{P}_{f}\right)$ & -1.57 & 1.53 & -1.56 & 1.21 & -1.25 & 1 \\
\hline \multicolumn{2}{|c|}{ 5\% critical values } & -3.50 & 6.73 & -2.93 & 4.86 & -1.95 & \\
\hline
\end{tabular}

Table 1 (contd') - Results of the integration tests on the series of real imports, real income and relative prices (all the variables are in logarithms); $\tau_{\tau}, \tau_{\mu}$ and $\tau$ are the Dickey-Fuller statistics for the hypothesis of integration in processes with trend and drift, with drift, and without trend and drift, respectively (Fuller, 1976, tab. 8.5.2); $\Phi_{1}$ and $\Phi_{3}$ are the Dickey-Fuller statistics for the hypothesis that the drift (respectively, the trend) is not statistically significant, conditional on the series being $I(1)$ (Dickey and Fuller, 1981, tab. IV and VI). 


\begin{tabular}{|c|c|c|c|c|c|c|c|c|}
\hline countries & $C R A D F$ & $\boldsymbol{p}$ & $C R A D F_{(L)}$ & break & $p$ & $C R A D F_{(R)}$ & break & $p$ \\
\hline Australia & -3.49 & $\mathbf{0}$ & $-5.78^{* *}$ & 1968 & $\mathbf{0}$ & $-5.79^{* *}$ & 1969 & $\mathbf{0}$ \\
\hline Austria & $-4.14^{* *}$ & $\mathbf{0}$ & & & & & & \\
\hline Belgium & -3.51 & 0 & $-6.35^{\text {** }}$ & 1998 & $\mathbf{0}$ & $-5.60^{* *}$ & 1991 & 2 \\
\hline Canada & -2.52 & $\mathbf{0}$ & -3.68 & 1976 & 1 & $-5.88^{* *}$ & 1994 & 1 \\
\hline Denmark & -2.20 & $\mathbf{0}$ & -4.50 & 1998 & $\mathbf{0}$ & $-5.85^{* *}$ & 1996 & 1 \\
\hline Finland & $-3.91^{*}$ & 1 & $-5.15^{* *}$ & 1964 & 1 & -4.56 & 1997 & 1 \\
\hline France & -3.09 & 0 & -4.12 & 1998 & $\mathbf{0}$ & -4.74 & 1986 & 0 \\
\hline Greece & -3.52 & $\mathbf{0}$ & -3.99 & 2002 & $\mathbf{0}$ & $-6.14^{* *}$ & 1984 & 1 \\
\hline Iceland & -3.55 & 1 & $-4.83^{*}$ & 1991 & 1 & $-5.28^{*}$ & 1989 & 1 \\
\hline Ireland & -2.41 & $\mathbf{0}$ & -3.49 & 1967 & $\mathbf{0}$ & -3.05 & 1967 & $\mathbf{0}$ \\
\hline Italy & -3.11 & $\mathbf{0}$ & -3.97 & 1967 & $\mathbf{0}$ & -4.09 & 1967 & $\mathbf{0}$ \\
\hline Japan & -1.73 & $\mathbf{0}$ & -3.51 & 1978 & $\mathbf{0}$ & -4.06 & 1978 & $\mathbf{0}$ \\
\hline Mexico & -2.57 & 1 & -3.82 & 1986 & $\mathbf{0}$ & -4.12 & 1986 & $\mathbf{0}$ \\
\hline Netherlands & -1.80 & 3 & $-4.88^{*}$ & 1998 & 3 & $-5.24^{*}$ & 1998 & 3 \\
\hline New Zealand & $-3.86^{*}$ & 0 & $-5.53^{* * *}$ & 1983 & $\mathbf{0}$ & -4.56 & 1983 & 0 \\
\hline Portugal & $-4.79^{* *}$ & 1 & & & & & & \\
\hline Spain & $-4.26^{* *}$ & $\mathbf{0}$ & & & & & & \\
\hline Sweden & -3.62 & $\mathbf{0}$ & $-6.59^{* *}$ & 1995 & $\mathbf{0}$ & $-6.34^{* *}$ & 1995 & $\mathbf{0}$ \\
\hline Switzerland & -2.94 & 2 & -3.37 & 1988 & 2 & -3.41 & 1972 & 2 \\
\hline Turkey & $-4.31^{* *}$ & 3 & & & & & & \\
\hline United Kingdom & -3.17 & $\mathbf{0}$ & $-5.22^{* *}$ & 1992 & $\mathbf{0}$ & $-5.69^{* *}$ & 1989 & 1 \\
\hline United States & $-4.24^{* *}$ & 0 & & & & & & \\
\hline $5 \%$ critical values & -4.11 & & -4.92 & & & -5.50 & & \\
\hline $\begin{array}{l}10 \% \\
\text { values }\end{array}$ & -3.73 & & -4.69 & & & -5.23 & & \\
\hline
\end{tabular}

Table 2 - Cointegration tests on the long-run standard import function (5); $C R A D F$ is the statistic of the CRADF test; $C R A D F_{(L)}$ is the Gregory and Hansen (1996) $C R A D F$ test in a model with level shift (see equation (10)); $C R A D F_{(R)}$ is the $C R A D F$ test in a model with regime shift (see equation (11)); $p$ is the number of lag of the dependent variable included in the auxiliary regressions of the $C R A D F$ tests. 


\begin{tabular}{lr|rr|rrr}
\hline \hline countries & $\hat{\pi}$ & $\hat{\pi}_{\mathrm{HM}}$ & $\hat{\pi}_{\mathrm{BD}}$ & break date & $\hat{\pi}_{1}$ & $\hat{\pi}_{2}$ \\
\hline Australia & 1.45 & 0.90 & & 1969 & 2.15 & 1.71 \\
Austria & 1.90 & & 2.24 & & & \\
Belgium & 1.72 & 1.94 & 2.64 & 1991 & 1.65 & 1.94 \\
Canada & 1.44 & 1.20 & 1.77 & 1994 & 1.24 & 1.31 \\
Denmark & 1.88 & 1.31 & 4.12 & 1996 & 1.60 & 3.09 \\
Finland & 1.26 & & 1.94 & 1964 & 1.37 & \\
France & 1.86 & 1.66 & 2.42 & & & \\
Greece & 3.17 & & 2.13 & 1984 & 3.50 & 2.18 \\
Iceland & 0.90 & & & 1989 & 1.35 & 0.80 \\
Ireland & 1.31 & & 2.63 & & & \\
Italy & 1.29 & 2.19 & 2.83 & & & \\
Japan & 2.04 & 1.23 & 1.51 & & & \\
Mexico & 1.69 & & & & & \\
Netherlands & 1.61 & 1.89 & 2.00 & 1998 & 1.56 & 2.75 \\
New Zealand & 1.83 & & & 1983 & 1.63 & \\
Portugal & 1.42 & 1.39 & 1.69 & & & \\
Spain & 1.91 & & 2.07 & & & \\
Sweden & 1.69 & 1.42 & 2.53 & 1995 & 1.57 & 1.76 \\
Switzerland & 2.38 & 1.81 & & & & \\
Turkey & 1.98 & & & & & \\
United Kingdom & 1.34 & 1.66 & 2.14 & 1989 & 1.11 & 2.12 \\
United States & 1.96 & 1.51 & 2.22 & & & \\
\hline \hline
\end{tabular}

Table 3 - Estimates of the long-run income elasticity of imports. $\hat{\pi}$ is the full sample estimate; $\hat{\pi}_{\mathrm{HM}}$ and $\hat{\pi}_{\mathrm{BD}}$ are, when available, the estimates provided by Houthakker and Magee (1969) and Bairam (1988) or (for Asian countries) Bairam and Dempster (1991); in the cases in which the Gregory and Hansen's test points out the existence of a structural break, $\hat{\pi}_{1}$ and $\hat{\pi}_{2}$ are the pre- and post-break estimates. Since Finland and New Zealand experiences a level, rather than a regime, shift, the estimates of the income elasticity do not change across the two subsamples. 


\begin{tabular}{|c|c|c|c|c|}
\hline & $\dot{X}$ & $\pi$ & $\dot{Y}_{B}$ & $\dot{Y}$ \\
\hline Australia & $6.05 \%$ & 1.45 & $4.17 \%$ & $3.64 \%$ \\
\hline Austria & $6.50 \%$ & 1.90 & $3.42 \%$ & $3.10 \%$ \\
\hline Belgium & $5.47 \%$ & 1.72 & $3.18 \%$ & $2.92 \%$ \\
\hline Canada & $5.57 \%$ & 1.44 & $3.87 \%$ & $3.26 \%$ \\
\hline Denmark & $5.14 \%$ & 1.88 & $2.73 \%$ & $2.22 \%$ \\
\hline Finland & $6.03 \%$ & 1.26 & $4.79 \%$ & $3.20 \%$ \\
\hline France & $6.14 \%$ & 1.86 & $3.30 \%$ & $2.68 \%$ \\
\hline Greece & $7.65 \%$ & 3.17 & $2.41 \%$ & $4.08 \%$ \\
\hline Iceland & $4.67 \%$ & 0.90 & $5.19 \%$ & $4.10 \%$ \\
\hline Ireland & $9.58 \%$ & 1.31 & $7.31 \%$ & $4.97 \%$ \\
\hline Italy & $6.40 \%$ & 1.29 & $4.96 \%$ & $2.98 \%$ \\
\hline Japan & $8.51 \%$ & 2.04 & $4.17 \%$ & $4.53 \%$ \\
\hline Mexico & $8.80 \%$ & 1.69 & $5.20 \%$ & $4.33 \%$ \\
\hline Netherlands & $5.94 \%$ & 1.61 & $3.69 \%$ & $3.00 \%$ \\
\hline New Zealand & $4.83 \%$ & 1.83 & $2.64 \%$ & $2.39 \%$ \\
\hline Portugal & $6.67 \%$ & 1.42 & $4.70 \%$ & $3.87 \%$ \\
\hline Spain & $7.96 \%$ & 1.91 & $4.17 \%$ & $4.07 \%$ \\
\hline Sweden & $5.79 \%$ & 1.69 & $3.42 \%$ & $2.65 \%$ \\
\hline Switzerland & $4.52 \%$ & 2.38 & $1.90 \%$ & $1.76 \%$ \\
\hline Turkey & $10.25 \%$ & 1.98 & $5.17 \%$ & $4.67 \%$ \\
\hline United Kingdom & $4.66 \%$ & 1.34 & $3.48 \%$ & $2.50 \%$ \\
\hline United States & $6.08 \%$ & 1.96 & $3.10 \%$ & $3.40 \%$ \\
\hline \multicolumn{4}{|c|}{ MAD } & $0.79 \%$ \\
\hline & & \multicolumn{2}{|c|}{$\rho$} & 0.69 \\
\hline & & \multicolumn{2}{|c|}{$\mathbf{t}$} & 4.26 \\
\hline
\end{tabular}

Table 4 - The balance of payments constrained growth rates and the actual growth rates in OECD economies. $\dot{X}$ is the growth rate of real exports, $\pi$ the income elasticity of imports, $\dot{Y}_{B}$ the balance of payments constrained growth rate, $\dot{Y}$ the actual growth rate, MAD the mean absolute deviation between $\dot{Y}_{B}$ and $\dot{Y}, \rho$ the Spearman rank correlation coefficient and $t$ the Student's $t$ statistic for the hypothesis $\rho=0$. 


\begin{tabular}{|c|c|c|c|c|c|c|c|c|c|}
\hline & \multirow[b]{2}{*}{ break date } & \multicolumn{4}{|c|}{ pre-break estimates } & \multicolumn{4}{|c|}{ post-break estimates } \\
\hline & & $\dot{X}$ & $\pi$ & $\dot{Y}_{B}$ & $\dot{Y}$ & $\dot{X}$ & $\pi$ & $\dot{Y}_{B}$ & $\dot{Y}$ \\
\hline Australia & 1969 & $7.73 \%$ & 2.15 & $3.60 \%$ & $4.99 \%$ & $5.64 \%$ & 1.71 & $3.30 \%$ & $3.31 \%$ \\
\hline Austria & & & & $3.42 \%$ & $3.10 \%$ & & & $3.42 \%$ & $3.10 \%$ \\
\hline Belgium & 1991 & $6.16 \%$ & 1.65 & $3.74 \%$ & $3.40 \%$ & $4.02 \%$ & 1.94 & $2.07 \%$ & $1.92 \%$ \\
\hline Canada & 1994 & $5.81 \%$ & 1.24 & $4.69 \%$ & $3.24 \%$ & $5.00 \%$ & 1.31 & $3.82 \%$ & $3.30 \%$ \\
\hline Denmark & 1995 & $4.91 \%$ & 1.60 & $3.07 \%$ & $2.25 \%$ & $5.83 \%$ & 3.06 & $1.91 \%$ & $2.10 \%$ \\
\hline Finland & 1964 & $5.05 \%$ & 1.37 & $3.69 \%$ & $4.78 \%$ & $6.13 \%$ & 1.37 & $4.47 \%$ & $3.05 \%$ \\
\hline Greece & 1984 & $9.51 \%$ & 3.50 & $2.72 \%$ & $5.45 \%$ & $5.63 \%$ & 2.18 & $2.58 \%$ & $2.59 \%$ \\
\hline Iceland & 1989 & $5.15 \%$ & 1.35 & $3.82 \%$ & $4.76 \%$ & $3.86 \%$ & 0.80 & $4.82 \%$ & $2.98 \%$ \\
\hline Netherlands & 1998 & $6.14 \%$ & 1.56 & $3.94 \%$ & $3.28 \%$ & $4.98 \%$ & 2.75 & $1.81 \%$ & $1.68 \%$ \\
\hline New Zealand & 1983 & $5.02 \%$ & 1.63 & $3.08 \%$ & $1.84 \%$ & $4.85 \%$ & 1.63 & $2.98 \%$ & $2.80 \%$ \\
\hline Portugal & & & & $4.70 \%$ & $3.87 \%$ & & & $4.70 \%$ & $3.87 \%$ \\
\hline Spain & & & & $4.17 \%$ & $4.07 \%$ & & & $4.17 \%$ & $4.07 \%$ \\
\hline Sweden & 1995 & $5.50 \%$ & 1.57 & $3.50 \%$ & $2.63 \%$ & $6.70 \%$ & 1.76 & $3.81 \%$ & $2.72 \%$ \\
\hline Turkey & & & & $5.17 \%$ & $4.67 \%$ & & & $5.17 \%$ & $4.67 \%$ \\
\hline United Kingdom & 1989 & $4.37 \%$ & 1.11 & $3.94 \%$ & $2.60 \%$ & $5.15 \%$ & 2.12 & $2.43 \%$ & $2.32 \%$ \\
\hline United States & & & & $3.10 \%$ & $3.40 \%$ & & & $3.10 \%$ & $3.40 \%$ \\
\hline MAD & & & & & $0.93 \%$ & & & & $0.48 \%$ \\
\hline$\rho$ & & & & & 0.17 & & & & 0.79 \\
\hline $\mathbf{t}$ & & & & & 0.65 & & & & 4.75 \\
\hline
\end{tabular}

Table 5 - The balance of payments constrained growth rates and the actual growth rates in OECD economies. $\dot{X}$ is the growth rate of real exports, $\pi$ the income elasticity of imports, $\dot{Y}_{B}$ the balance of payments constrained growth rate, $\dot{Y}$ the actual growth rate, MAD the mean absolute deviation between $\dot{Y}_{B}$ and $\dot{Y}, \rho$ the Spearman rank correlation coefficient and $t$ the Student's $t$ statistic for the hypothesis $\rho=0$. 


\begin{tabular}{lrrr}
\hline \hline & \multicolumn{1}{c}{$\begin{array}{l}\text { whole } \\
\text { sample }\end{array}$} & pre-break & post-break \\
\hline$a$ & 0.00 & 0.03 & 0.00 \\
& $(0.53)$ & $(0.00)$ & $(0.97)$ \\
$b$ & 1.03 & 0.11 & 1.13 \\
& $(0.00)$ & $(0.50)$ & $(0.00)$ \\
\hline $\bar{R}^{2}$ & 0.517 & -0.03 & 0.681 \\
$F(a=0)$ & 0.53 & 0.00 & 0.97 \\
$F(b=1)$ & 0.88 & 0.00 & 0.50 \\
$F(a=0 ; b=1)$ & 0.01 & 0.00 & 0.04 \\
\hline$L M I$ & 0.92 & 0.80 & 0.10 \\
$L M O$ & 0.07 & 0.10 & 0.91 \\
$L M N$ & 0.05 & 0.85 & 0.07 \\
$L M F$ & 0.61 & 0.02 & 0.31 \\
\hline \hline
\end{tabular}

Table 6 - OLS estimates of equation (5). The $p$-values of the $t$ tests are reported in parentheses under the coefficients. $F(a=0), \quad F(b=1)$ and $F(a=0 ; b=1)$ are the $p$-values of the $F$ tests for the corresponding hypotheses. $L M I, L M O, L M N$ and $L M F$ are the $p$-values of the Lagrange multiplier tests for the hypothesis of non autocorrelation, homoskedasticity and normality of the residuals, and of linearity of the regression function, respectively.

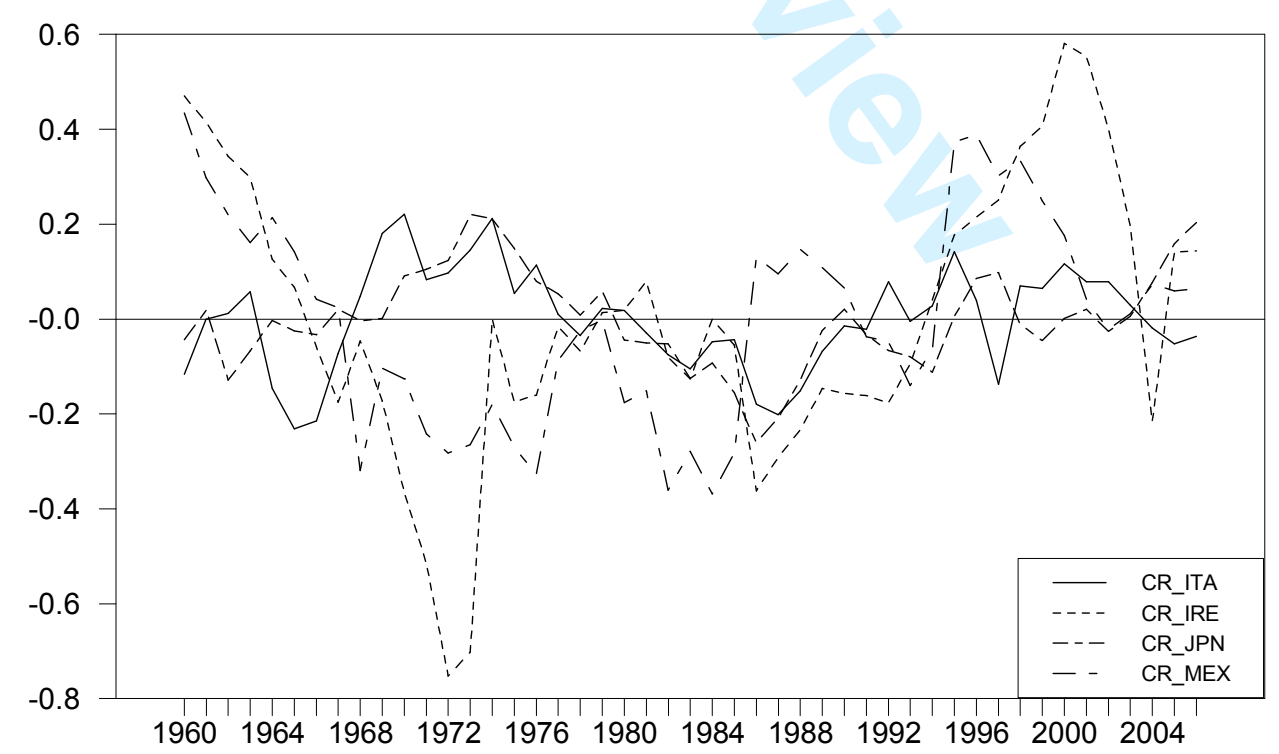

Figure 1- The cointegrating residual in Ireland, Italy, Japan and Mexico. 